\title{
Impact of DOTS expansion on tuberculosis related outcomes and costs in Haiti
}

\author{
Vary Jacquet $^{\dagger 1}$, Willy Morose ${ }^{\dagger 1}$, Kevin Schwartzman ${ }^{\dagger 2}$, Olivia Oxlade ${ }^{\dagger 2}$, \\ Graham Barr $^{\dagger 3}$, Franque Grimard ${ }^{\dagger 4}$ and Dick Menzies* ${ }^{* 2}$
}

\begin{abstract}
Address: ${ }^{1}$ National tuberculosis control programme, Port-au-Prince, Haiti, ${ }^{2}$ Respiratory Epidemiology Unit, Montreal Chest Institute, McGil University, Montreal, Canada, ${ }^{3}$ Departments of Medicine and Epidemiology, Columbia University Medical Center, New York, NY, USA and ${ }^{4}$ Department of Economics, McGill University, Montreal, Canada

Email: Vary Jacquet - varyj@yahoo.com; Willy Morose - omerso54@yahoo.com; Kevin Schwartzman - kevin.schwartzman@mcgill.ca; Olivia Oxlade - olivia.oxlade@mcgill.ca; Graham Barr - rgb9@columbia.edu; Franque Grimard - fgrima@po-box.mcgill.ca;

Dick Menzies* - dick.menzies@mcgill.ca

* Corresponding author †Equal contributors
\end{abstract}

Published: 15 August 2006

BMC Public Health 2006, 6:209 doi:10.1 186/147|-2458-6-209

This article is available from: http://www.biomedcentral.com/147I-2458/6/209

(C) 2006 Jacquet et al; licensee BioMed Central Ltd.

This is an Open Access article distributed under the terms of the Creative Commons Attribution License (http://creativecommons.org/licenses/by/2.0), which permits unrestricted use, distribution, and reproduction in any medium, provided the original work is properly cited.
Received: 10 February 2006

Accepted: 15 August 2006

\begin{abstract}
Background: Implementation of the World Health Organization's DOTS strategy (Directly Observed Treatment Short-course therapy) can result in significant reduction in tuberculosis incidence. We estimated potential costs and benefits of DOTS expansion in Haiti from the government, and societal perspectives.

Methods: Using decision analysis incorporating multiple Markov processes (Markov modelling), we compared expected tuberculosis morbidity, mortality and costs in Haiti with DOTS expansion to reach all of the country, and achieve WHO benchmarks, or if the current situation did not change. Probabilities of tuberculosis related outcomes were derived from the published literature. Government health expenditures, patient and family costs were measured in direct surveys in Haiti and expressed in 2003 US\$.

Results: Starting in 2003, DOTS expansion in Haiti is anticipated to cost $\$ 4.2$ million and result in 63,080 fewer tuberculosis cases, 53,120 fewer tuberculosis deaths, and net societal savings of $\$ 131$ million, over 20 years. Current government spending for tuberculosis is high, relative to the per capita income, and would be only slightly lower with DOTS. Societal savings would begin within 4 years, and would be substantial in all scenarios considered, including higher HIV seroprevalence or drug resistance, unchanged incidence following DOTS expansion, or doubling of initial and ongoing costs for DOTS expansion.
\end{abstract}

Conclusion: A modest investment for DOTS expansion in Haiti would provide considerable humanitarian benefit by reducing tuberculosis-related morbidity, mortality and costs for patients and their families. These benefits, together with projected minimal Haitian government savings, argue strongly for donor support for DOTS expansion. 


\section{Background}

Between 1997 and 2002 the incidence of active TB increased in most low and middle income countries [1]. This occurred despite the availability of adequate tools for diagnosis and treatment, and an effective TB control strategy - which has been labelled DOTS. This strategy, originally developed in sub-Saharan Africa, is being promoted by the World Health Organisation (WHO) [2] because it is feasible in high-burden settings [3], cost-effective even in low income countries [4], and can result in substantial reduction in TB incidence [5].

However, between $\$ 290$ - \$500 million (US) is required annually for the additional training, equipment and infrastructure needed to implement and maintain DOTS in all low and middle income countries [6,7]. As a result DOTS expansion has lagged considerably behind WHO targets [8].

In the America's, Haiti is the poorest country [9], with the highest incidence of smear positive pulmonary TB (138/ 100,000 in 2002) [8] and HIV seroprevalence (4.5\% in 2002) [10]. In 2002 the WHO estimated that only $37 \%$ of the population had access to DOTS programmes [11], only $49 \%$ of all smear positive cases were diagnosed, and only $71 \%$ of those diagnosed were successfully treated [8]. We have compared projected TB related outcomes and costs if the current control programme is maintained (status quo), or if DOTS is expanded to reach WHO benchmarks, for $100 \%$ of the population in Haiti.

\section{Methods \\ General description of model and the two strategies compared}

We developed a decision analysis model, incorporating multiple Markov processes, (Markov modelling) using Tree-Age Pro Release 6.0, (Tree-age Inc., Williamstown, $\mathrm{MA})$. This model calculated the probability of TB-related events expected to result over 20 years, starting in 2003, from two alternate strategies for TB control. These probabilities were calculated for a hypothetical fixed cohort with the age structure, socio-demographic and health characteristics and size of the population of Haiti in 2002. The information on the population of Haiti, summarized in Table 1, was taken from publicly accessible information provided by international agencies including the World Bank, WHO, and the United Nations Program on AIDS (UNAIDS) [8-10].

The strategies compared were to continue the present national TB control programme (status quo), or DOTS expansion. With the status quo strategy there would be no change over the 20 year time frame of the analysis, from January 2003 levels of: DOTS coverage [11], case finding [8], treatment outcomes [8], incidence of smear positive
TB [8], prevalence of initial TB drug resistance [12,13], and HIV seroprevalence [10]. Since incidence of disease did not change with the status quo, risk of TB infection [14], and LTBI prevalence also remained unchanged throughout the period of analysis. Current levels of DOTS coverage have been achieved with assistance from foreign donors - hence we implicitly accounted for current foreign assistance. However, we did not explicitly add in these expenditures, since they would have been added to both strategies, making both more expensive, but without changing the differences between them.

With DOTS expansion, we assumed that DOTS would be expanded from the level of coverage in January 2003, (Year 1) [11], to reach $100 \%$ of government health facilities by the end of Year 3. Case detection would increase from current WHO estimated levels [8] to 70\%, and treatment success (cure and treatment completion) to $85 \%$ the WHO targets [3], although treatment failure and TB mortality would not change [8]. Rates of initial drug resistance [12,13] and HIV prevalence [10] would not change with DOTS over the full 20 years. DOTS implementation would halve pre-diagnostic health system visits $[15,16]$, and health system delays [17-19], although patient delays would not change. Hospitalisation duration would decrease by two-thirds $[15,16]$. The number of patients investigated for each new case of TB diagnosed would increase from 4 to 16 [20]. Retreatment failures (multi-drug resistant TB) would be treated with second line drugs obtained from the Green Light Committee [21] with $48 \%$ cure, and $12 \%$ mortality [22]. Most importantly DOTS expansion was assumed to result in a $6 \%$ annual decline in incidence, as described in Peru following national DOTS implementation [5]. This would produce corresponding reductions in the risk, and prevalence of TB infection [14].

\section{Health states and transitional probabilities (see Figure I)}

At the start of Year 1 (assumed to be 2003), cohort members were considered to be in one of five TB-related states, and one of three HIV-related states. The TB-related states were: 1) no tuberculosis infection; 2) recent latent tuberculosis infection (LTBI) - acquired within 2 years; and, 3) long-standing LTBI - acquired more than 2 years ago; 4 ) active tuberculosis; and, 5) treated, or spontaneously resolved active TB. States 2-5 were further sub-classified into 3 groups: drug-sensitive, single-drug resistant, or multi-drug resistant $\mathrm{TB}$ - with likelihood based on surveys of drug resistance in Haitian populations [12,13]. The proportion with recent or long-standing LTBI was calculated based on the age structure of the population [23], and incidence of smear-positive active disease [8], using the Styblo formula [14]. 
Table I: Summary of key input data for Haiti in 2002(All costs in US dollars)

\begin{tabular}{|c|c|c|c|}
\hline EPIDEMIOLOGIC/PROGRAMME DATA & HAITI & REFERENCE/SOURCE & \\
\hline Population (2002) & 8.3 million & \multicolumn{2}{|l|}{ [9] } \\
\hline Gross National Income annual per capita (US\$) & $\$ 440$ & \multicolumn{2}{|l|}{ [9] } \\
\hline Life expectancy at birth & 52.0 & \multicolumn{2}{|l|}{$[9]$} \\
\hline All cause mortality & Age specific & \multicolumn{2}{|l|}{$[44]$} \\
\hline Incidence new smear positive TB per 100,000 (200I) & 138 & \multicolumn{2}{|l|}{$[8]$} \\
\hline Annual risk of TB infection (ARI) & $2.26 \%$ & \multicolumn{2}{|c|}{ Calculated from [14] and [8] } \\
\hline Prevalence of $L T B I$ at age 20 & $41 \%$ & \multicolumn{2}{|c|}{ Calculated from [14] } \\
\hline Likelihood of diagnosis and treatment of LTBI & $1 \%$ & \multicolumn{2}{|c|}{$[59] *$} \\
\hline Completion of LTBI Treatment & $67 \%$ & \multicolumn{2}{|l|}{$[60]$} \\
\hline Efficacy of 9 INH - INH Sensitive & $90 \%$ & \multicolumn{2}{|l|}{$[6 I]$} \\
\hline INH Resistant & 0 & \multicolumn{2}{|l|}{ [62] } \\
\hline Prevalence of HIV infection - 2002 & $4.5 \%$ & \multicolumn{2}{|c|}{$[10]$} \\
\hline Incidence of HIV infection & $0.46 \% /$ year & \multicolumn{2}{|c|}{ Calculated from [35] } \\
\hline DOTS Coverage - 2002 & $37 \%$ & \multicolumn{2}{|c|}{$[\mathrm{II}]$} \\
\hline Case detection rate -2001 & $49 \%$ & \multicolumn{2}{|l|}{$[8]$} \\
\hline \multicolumn{4}{|l|}{ Drug Resistance } \\
\hline Single drug resistance & $20 \%(11 \%-31 \%)$ & \multicolumn{2}{|c|}{ [12] } \\
\hline Multi drug resistance (HR) & $0.3 \%(0-4 \%)$ & \multicolumn{2}{|l|}{$[12 ; 63]$} \\
\hline Treatment outcomes New cases - 2001 & Overall [8] & DOTS areas (NTP) & Non-DOTS \\
\hline Cure/complete & $71 \%$ & $85 \%$ & $63 \%$ \\
\hline Default/transfer/not evaluated & $23 \%$ & $9 \%$ & $31 \%$ \\
\hline Die & $5 \%$ & $5 \%$ & $5 \%$ \\
\hline Fail & $1 \%$ & $1 \%$ & $1 \%$ \\
\hline Outcomes Re-treatment cases - 200I & Overall [8] & DOTS areas (NTP) & Non-DOTS \\
\hline Cure/complete & $54 \%$ & $80 \%$ & $39 \%$ \\
\hline Default/transfer/not evaluated & $29 \%$ & $4 \%$ & $44 \%$ \\
\hline Die & $8 \%$ & $8 \%$ & $8 \%$ \\
\hline Fail & $8 \%$ & $8 \%$ & $8 \%$ \\
\hline
\end{tabular}

Notes:

* - This assumes only dually infected (HIV and TB infection) whose HIV infection is detected and are tuberculin tested at a limited number of screening centres will be treated.

NTP - data on treatment outcomes in areas with DOTS, from cohort reports to National TB programme

Key pathogenetic model assumptions regarding reactivation and cure rates for HIV-negative and HIV-positive individuals, summarized in Table 2, were based on published cohort studies and randomized trials. In HIV negative persons, active TB would develop in the first two years after new TB infection in 5\% of the population [24]. In other studies the risk of disease in the first two years after new TB infection ranged from $4 \%$ [25] to $10 \%$ [26]. Given the $80 \%$ protective effect afforded by previous latent $\mathrm{TB}$ infection in HIV uninfected persons [27], re-infection would be followed by a $1 \%$ risk of active TB in the first two years. In latently infected persons risk would be $0.1 \%$ annually after the first two years - based on prospective follow-up of two tuberculin positive cohorts - of young military recruits [28], and Vietnamese refugees [29].

The probability of transfer out and default varied by strategy. We assumed that the treatment outcome of "transferred-out" was equivalent to default [30]. For individuals who defaulted from therapy we assumed an overall cure rate of $62 \%$, calculated from the proportion of defaulters after different lengths of therapy [31], and cure rates in randomised trials of regimens of 3 or 4 months duration [32-34].

The HIV-related states were: 1) no HIV infection; 2) early HIV, defined as having no clinical manifestations; or, 3 ) late HIV infection - defined as clinical AIDS. HIV-related survival and annual rates of transition from early to late HIV states were based on a Ugandan cohort [35]. Probability of acquiring HIV infection was the same in both strategies. Annual risk of HIV infection was estimated to be $0.49 \%$ - calculated from the general population prevalence [10] divided by the average years of survival in a low-income setting [35] (and thus assumed to be uniform for the entire population). We assumed no consequence of HIV re-infection.

The same model was used for HIV infected or uninfected. The proportion of HIV infected persons entering the model was 0.045 - corresponding to the estimated seroprevalence in Haiti in 2002 (10). Every year, $0.5 \%$ of the uninfected population could acquire new HIV infection, thus changing from an HIV uninfected to an HIV infected 


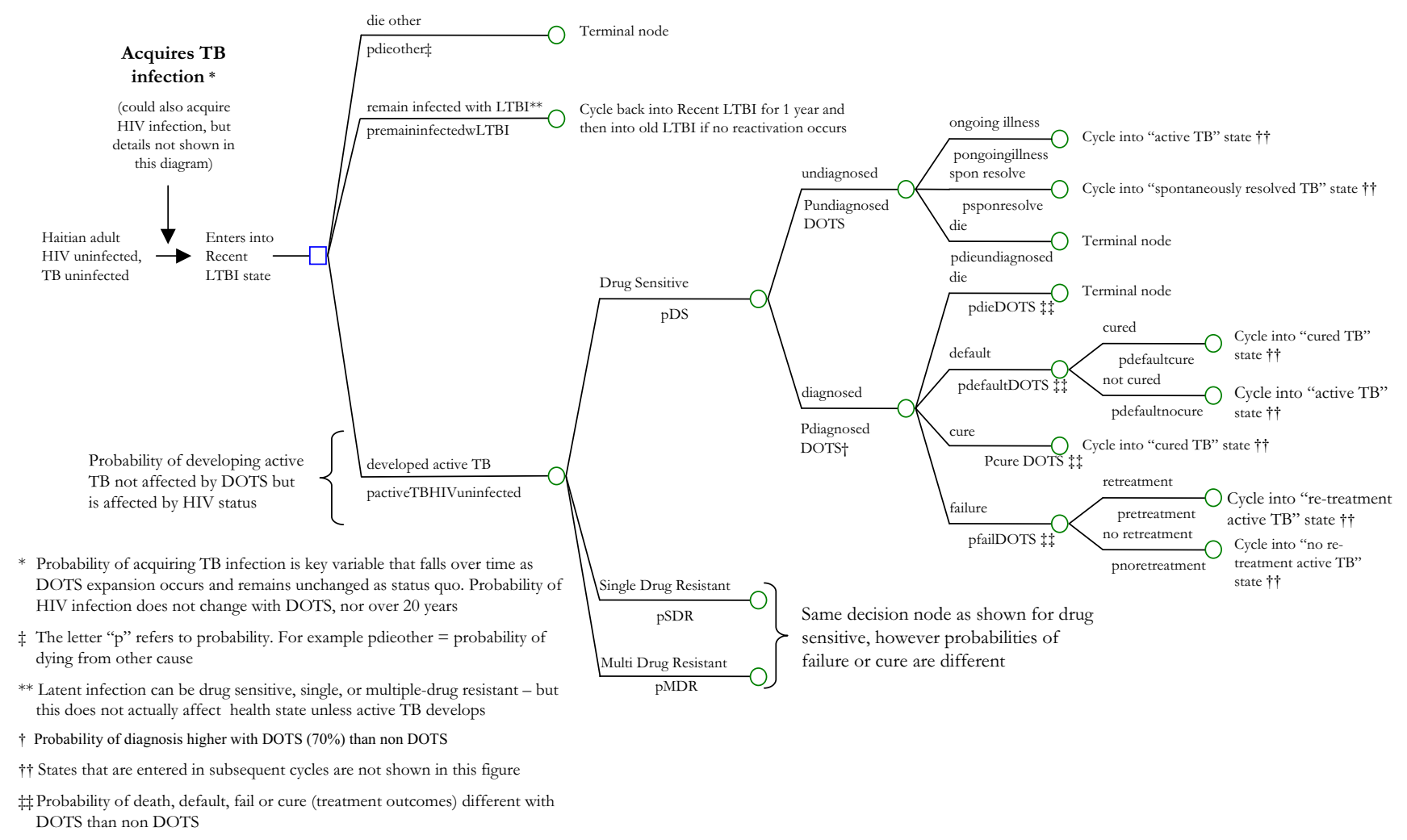

Figure I

Sample decision analysis tree for Haitian adult, initially without TB infection, nor HIV infection who acquires new TB infection.

state. The major difference in the model for HIV infected and uninfected was in regard to the probability of development of active TB following TB infection and mortality - without TB, or during and after treatment for active TB. The risk of active TB in persons with LTBI, and HIV infection has been studied in a number of settings. We could find only one study that categorized cohort members into the states of new or old TB infection and early or late HIV [36]. This was used for the base case estimate of 3.4\% annual risk of active TB disease in persons with longstanding LTBI and HIV infection.

We could not find published estimates of risk of disease following new TB infection in HIV infected individuals. Therefore we extrapolated from HIV negative persons, in whom the risk of development of active TB following new LTBI infection is 20-50 times higher than with longstanding LTBI [24-26]. Given the 3.4\% annual risk of active TB in early HIV infection and long-standing LTBI [36], we assumed the risk of TB disease would be 10 times higher, or 34\% per year during the first two years following new TB infection.
Response to treatment of TB disease was not affected by HIV infection. HIV-infected individuals with smear positive active TB were assumed to have no chance of spontaneous cure - hence $100 \%$ mortality without treatment. If treated, TB mortality would be 2.25 times higher during treatment [37-39], and 2.2 times higher after treatment $[3,40,41]$. Mortality from active TB disease with MDR strains would be $100 \%[42,43]$.

\section{Model calculations}

Beginning in 2003 (Year 1), the model determined the proportion of the cohort developing smear positive active $\mathrm{TB}$, dying from $\mathrm{TB}$, or dying from other causes in each year for 20 successive years. The risk of death from other causes was derived from the age distribution and HIV sero-prevalence of the cohort, and country-specific life tables published by WHO [44]. The probability of TB related outcomes depended on cohort members' TB and HIV related states (infected or not, and new or old), as detailed above, and summarized in Table 2. Clinical outcomes also varied according to whether each TB related state was diagnosed and treated. 
Table 2: Probabilities of outcomes with different TB and HIV health states

\begin{tabular}{|c|c|c|c|}
\hline PATHOGENETIC FACTOR & BASE & RANGE & REFERENCE \\
\hline \multicolumn{4}{|l|}{ Reactivation from latent TB infection } \\
\hline \multicolumn{4}{|l|}{ Present more than 2 years ("long-standing LTBI")* } \\
\hline HIV uninfected & $0.1 \% /$ year & $0.1 \%-0.2 \% /$ year & {$[28 ; 29]$} \\
\hline HIV infected - asymptomatic & $3.4 \% /$ year & $3.4 \%-8.7 \%$ & {$[36 ; 64 ; 65]$} \\
\hline HIV infected - AIDS & $33 \% /$ year & $33 \%-67 \%$ & [36] \\
\hline \multicolumn{4}{|l|}{ Within 2 years of new TB infection ("recent LTBI") } \\
\hline HIV uninfected & $5 \%$ & $2 \%-15 \%$ & {$[24 ; 66]$} \\
\hline HIV infected - asymptomatic & $33 \%$ & $33 \%-100 \%$ & Extrapolated \\
\hline HIV infected - AIDS & $100 \%$ & $50 \%-100 \%$ & {$[42 ; 43 ; 67-69]$} \\
\hline \multicolumn{4}{|l|}{ Within 2 years following re-infection } \\
\hline HIV Uninfected & $1 \%$ & & {$[27 ; 70]^{*}$} \\
\hline HIV infected & $33 \%$ or $100 \%$ & & Assumption \\
\hline \multicolumn{4}{|l|}{ Outcomes of untreated smear positive TB } \\
\hline Mortality - I year, \& 2 years & $33 \%, \& 50 \%$ & & From [7I] \\
\hline Spontaneous remission & $25 \%$ & & {$[72]$} \\
\hline Relapse after spontaneous remission & $2.5 \% / y e a r$ & $1.3 \%-2.5 \% / y e a r$ & {$[72 ; 73]$} \\
\hline \multicolumn{4}{|l|}{ Outcomes of treated smear positive TB } \\
\hline Relapse after cure (total over next 2 years) & $3.0 \%$ & $1.5 \%-5 \%$ & [74-78] \\
\hline Cure rate if default (SDR or drug sensitive) $* *$ & $62.4 \%$ & & {$[31-34]$} \\
\hline \multicolumn{4}{|l|}{ Effect of drug sensitivity or treatment outcomes } \\
\hline Relative risk of failure/if single drug resistant & 2.0 & & [79] \\
\hline Relative risk of failure/if multi-drug resistant & 10.5 & & [79] \\
\hline Relative risk of death/if single drug resistant & 1.0 & & [79] \\
\hline Relative risk of death/if multi-drug resistant & 4.5 & & [79] \\
\hline If MDR - Probability of cure with treatment & $48 \%$ & $48 \%-73 \%$ & {$[22 ; 80]$} \\
\hline - Probability of death with treatment & $12 \%$ & $12 \%-26 \%$ & {$[22 ; 80]$} \\
\hline \multicolumn{4}{|l|}{ HIV Infected and TB } \\
\hline Average duration of HIV infection - Total & 9.8 years & $7.3-9.8$ & {$[35 ; 81]$} \\
\hline - Time spent in HIV asymptomatic state & 9.0 years & & [35] \\
\hline Annual risk of progression of asymptomatic HIV to AIDS & $7 \%$ & $7 \%-9 \%$ & {$[35 ; 81]$} \\
\hline Annual risk of death from HIV: HIV asymptomatic state & $4.6 \%$ & & [35] \\
\hline Annual risk of death from HIV: AIDS & $22 \%$ & & [35] \\
\hline Effect of prior active TB on relative risk of death from HIV & 2.2 & $(2.2-4.0)$ & {$[3 ; 40 ; 4 I]$} \\
\hline $\begin{array}{l}\text { Effect of HIV infection on relative risk of death during TB treatment (drug sensitive or } \\
\text { single drug resistance) }\end{array}$ & 2.25 & & {$[37-39 ; 82]$} \\
\hline Relapse after successful TB treatment (cured) & $3.1 \%$ & $3.1 \%-6.4 \%$ & [83-85] \\
\hline
\end{tabular}

* Assume that rate of reactivation more than two years after TB infection is the same whether it is after a first infection, or after re-infection.

** Transfer out considered equivalent to default [30]. Overall cure rate if default based on timing of default (from [3I]), and cure rates from trials of very short course treatment [32-34].

Cohort members who survived to the end of each year in the model, entered the following year of the simulation. Health states at the beginning of each year depended on the events during the preceding year. As a (simplified) example, some members of the cohort entered Year 1 in the health state of no TB infection. If they survived Year 1 without acquiring TB or HIV infection they entered Year 2 in the same state. However if they acquired new TB infection during Year 1, they entered Year 2 in the "new TB infection" state. During Year 2, they could develop active TB (with probability as shown in Table 2), die from other causes, or remain with new TB infection (entering Year 3 with this health state). If they developed active TB they could be diagnosed and treated, or remain undiagnosed. Likelihood of diagnosis, and treatment outcomes varied according to the strategy being analyzed (see Table 1), and underlying drug resistance. The probability of having pansensitive, single drug resistant, or multi-drug resistant underlying strains, was determined from two surveys of initial drug resistance in Haitian TB patients $[12,13]$. If undiagnosed they could die of TB (probability in Table 2) or other causes (from Life Tables), or survive and enter Year 3 with undiagnosed TB disease.

The model generated a single value for the cumulative proportion of the cohort that developed active TB, died of $\mathrm{TB}$, or died of other causes throughout the 20 years for each strategy. This was then multiplied by the size of the population to generate expected total number of persons developing each outcome over the period of analysis. 


\section{Costs}

Costs were estimated from societal, and governmental perspectives [45]. Costs modelled from the government perspective included TB-related health care costs for governments and health care providers, plus costs for DOTS implementation, maintenance, and drug costs. TB related costs from the societal perspective included government costs, plus patients' and families' out-of-pocket expenditures, lost wages (including time caring for ill family members), plus productivity losses resulting from disability and death [45]. All costs were expressed in 2003 US dollars, and all future expenditures and outcomes were discounted 3\% annually [46].

A questionnaire regarding the household impact of fatal adult illness [47] was adapted, pre-tested in Montreal, and translated into French and Creole - to measure out-ofpocket costs and lost income for patients and families for pre-diagnostic, hospitalisation, treatment and follow-up visits. This was administered by trained interviewers to 84 consenting adults in their second and third months of therapy for new smear positive pulmonary $\mathrm{TB}$, at the same facilities where health system costs were ascertained. To estimate government TB expenditures, we surveyed administrators of 8 rural, and 8 urban health facilities, including 3 TB sanatoria, 5 general hospitals, 5 general clinics, and 3 TB dispensaries. This study was approved by the Institutional Review Board of McGill University, and the National TB control programme of Haiti.

Costs for DOTS implementation and maintenance were based on a DOTS expansion project in Ecuador [48], prorated to Haiti, based on their respective per capita gross national incomes [49]. Drug costs were calculated from the model estimates of number of new and retreatment cases, and unit costs from the Global Drug Facility [50]. Patients with active TB were assumed to be $50 \%$ disabled (productivity loss) from symptom onset until diagnosis, unable to work while hospitalised, and 50\% disabled for the remainder of the first two months of treatment [1719]. Patients who were not diagnosed or who failed treatment were assumed to have 50\% disability throughout their illness. Productivity loss from death in HIV uninfected was estimated as per capita annual income [9] times the number of years remaining in the model, with appropriate discounting [46]. For HIV infected the productivity loss was estimated based on the number of years they would be anticipated to survive after development of active TB based on total survival of 9.8 years (35) and the number of years they had survived with HIV infection before developing active TB.

\section{Sensitivity analyses}

We conducted extensive one-way sensitivity and threshold analyses, to assess the robustness of our findings to variations in key assumptions. Each parameter was varied individually, except for pathogenetic parameters that were based on well characterized, carefully studied cohorts. We examined the effect of varying rates of decline in tuberculosis incidence following DOTS expansion, increasing HIV seroprevalence and drug resistance, case detection rate, and higher costs of DOTS implementation, maintenance and drugs. Where possible, sensitivity analyses reflected ranges from the published literature. If these were not available, other variations were used such as halving or doubling costs. We also modelled composite "best case" and "worst case" scenarios, based on combinations of favourable and unfavourable assumptions for influential model assumptions - reflecting findings of the initial one-way sensitivity analyses.

\section{Results}

As shown in Table 3, current government expenditures averaged $\$ 432$ per TB patient, of which hospital services accounted for $64 \%$, and TB drugs less than 5\%. For the 84 TB patients and families surveyed, total TB related out-ofpocket expenses, and lost income averaged \$334 - equivalent to $76 \%$ of average per capita income of Haitians in 2002. Of 34 patients who could compare earnings before onset of TB and at the time of the survey, $9(26 \%)$ had a significant drop in income (average 65\%), while only one (3\%) reported increased income.

With the status quo strategy, 226,590 TB cases, and 107,070 TB-related deaths are projected to occur in Haiti over 20 years (Table 4 ). This morbidity and mortality will result in total societal costs of $\$ 378$ million, including government costs of $\$ 59$ million. The DOTS expansion strategy is projected to avert $63,080 \mathrm{~TB}$ cases, prevent $53,120 \mathrm{~TB}$ deaths, and result in societal savings of $\$ 131$ million, over 20 years. Of the societal savings, $73 \%$ will result from deaths averted, and $20 \%$, or approximately $\$ 26$ million would reflect savings for patients and their families.

We project a reduction in government expenditures for hospital services from $\$ 38$ million to $\$ 22$ million. However these savings would be offset by the need for initial investment for DOTS expansion, plus increased recurrent government expenditures for smear microscopy, directly observed treatment, multi-drug resistant (MDR) TB treatment, supervision, training, and quality control. As a result, net government savings are projected to be only $\$ 4$ million over the full 20 years.

The substantial societal savings with DOTS expansion was robust in all sensitivity analyses, including doubling the prevalence of drug resistance, or doubling the costs for initial DOTS expansion, for TB drugs, or for ongoing supervision and training (Table 5). Of note - even if the 
Table 3: Summary of health system and patient costs in Haiti

\begin{tabular}{|c|c|c|c|}
\hline & MEAN & (SD) & SOURCE \\
\hline \multicolumn{4}{|l|}{ Pre-Diagnosis } \\
\hline Total Time (onset of symptoms to diagnosis) & 4.4 months & (3.5 months) & PCQ \\
\hline Number of Visits & 4.7 & $(7.2)$ & PCQ \\
\hline Cost to health system for visits (total) & $\$ 16.31$ & & \\
\hline Lab costs (per patient - 3AFB smears) & $\$ 4.46$ & $(--)$ & [53] \\
\hline Patients out-of-pocket: for visits (total) & $\$ 40.55$ & $(\$ 138)$ & PCQ \\
\hline Miscellaneous & $\$ 22.87$ & $(\$ 116.85)$ & PCQ \\
\hline Lost income for patient/family: for visits & $\$ 6.19 *$ & & PCQ \\
\hline Miscellaneous & $\$ 61.71 *$ & & PCQ \\
\hline
\end{tabular}

Hospitalization

$N(\%)$ hospitalized

Average length of stay (for all 84)

Health system costs (per patient)

Patient out-of-pocket (per hospitalization)

Lost income for patients and family
47 (56\%)
21.3 days
$\$ 321.00$
$\$ 92.69$
$\$ 29.40 *$

$\begin{array}{ll}(27.2) & \text { PCQ } \\ (--) & \text { HFQ } \\ (\$ 323.41) & \text { PCQ } \\ (\$ 44.37) & \text { PCQ }\end{array}$

Direct Observation of Treatment (DOT)

\begin{tabular}{|c|c|c|c|}
\hline Number of visits & 75 & -- & NTP \\
\hline$N(\%)$ on DOT & $43(51 \%)$ & -- & \\
\hline Health system costs: for DOT (total) & $\$ 48.75$ & -- & HFQ \\
\hline For drug costs (new case) & $\$ 20.93$ & -- & $* *$ \\
\hline Patient out-of-pocket expenses (total) & $\$ 56.25$ & $(\$|4| .00)$ & PCQ \\
\hline Lost income for patient and family & $\$ 20.40 *$ & $(\$ 25.50)$ & PCQ \\
\hline
\end{tabular}

Follow-up (Medical Check Up)

\begin{tabular}{|c|c|c|c|}
\hline Number of visits & 6 & -- & NTP \\
\hline Health system costs (total) & $\$ 20.82$ & -- & HFQ \\
\hline Patient out-of-pocket expenses & $\$ 1.88$ & $(\$ 1 \mid .65)$ & PCQ \\
\hline Lost income for patient and family & $\$ 2.35^{*}$ & $(\$ 3.67)$ & PCQ \\
\hline
\end{tabular}

Total cost per TB patient treated

$\begin{array}{ll}\text { Health system } & \$ 432.27 \\ \text { Patient and Family: out-of-pocket costs } & \$ 214.24 \\ \quad \text { Lost Income } & \$ 120.05 \\ \text { Total patients and families } & \$ 334.29\end{array}$

Notes:

$*$ Income $=\$ 0.17$ (US) per hour based on average per capita GNI $(\$ 440)$ (reference 9$) / 2496$ hours (= 48 hours $\times 52$ weeks)

$\mathrm{PCQ}=$ Patient cost questionnaire

$\mathrm{HFQ}=$ Health facility questionnaire

NTP = National TB programme guidelines

** $=$ Prices for drugs in DOTS areas from [86], and 1.4 times higher in non-DOTS areas [15;16]

incidence did not decline at all under DOTS expansion, DOTS is still predicted to result in substantial society savings through reduced mortality and reduced costs for patients and their families. However, government savings were much more susceptible to changes in assumptionsreflecting the very modest government savings in the base case analysis. Haitian government savings would be sig- nificant only if foreign donors supported the costs for DOTS expansion.

As seen in Figure 2, the DOTS expansion strategy would begin to result in societal savings within 4 years, although government savings would only begin after 15 years. A small increase in HIV sero-prevalence would result in a 
Table 4: Projected cumulative TB incidence, related mortality, and costs with two strategies for TB control in Haiti: base case analysis

TOTAL COSTS (SAVINGS) (\$US MILLIONS)

PERSPECTIVE

TOTAL TB CASES TOTAL TB DEATHS SOCIETAL GOVERNMENT

\begin{tabular}{|c|c|c|c|c|}
\hline \multicolumn{5}{|l|}{ AFTER ONLY 5 YEARS } \\
\hline - Status Quo & 64,740 & 25,730 & $\$ 77$ & $\$ 16$ \\
\hline - DOTS expansion & 59,760 & 19,090 & $\$ 70$ & $\$ 21$ \\
\hline $\begin{array}{l}\text { - Cases or deaths averted and added costs or } \\
\text { (net savings) with DOTS }\end{array}$ & 4,980 & 6,640 & $(\$ 7)$ & $\$ 5$ \\
\hline \multicolumn{5}{|l|}{ AFTER IO YEARS } \\
\hline - Status Quo & 125,330 & 54,780 & $\$ 173$ & $\$ 32$ \\
\hline - DOTS expansion & 103,750 & 34,030 & $\$ 134$ & $\$ 35$ \\
\hline $\begin{array}{l}\text { - Cases or deaths averted and added costs or } \\
\text { (net savings) with DOTS }\end{array}$ & 21,580 & 20,750 & $(\$ 39)$ & $\$ 3$ \\
\hline \multicolumn{5}{|l|}{ Over Full 20 Years } \\
\hline - Status Quo & 226,590 & 107,070 & $\$ 378$ & $\$ 59$ \\
\hline - DOTS expansion & 163,510 & 53,950 & $\$ 248$ & $\$ 55$ \\
\hline - Cases or deaths averted and (net savings) with DOTS & 63,080 & 53,120 & $(\$ 131)$ & $(\$ 4)$ \\
\hline
\end{tabular}

substantial increase in the number of TB cases, deaths, and TB-related societal costs (Figure 3), although savings with DOTS would be greater. As seen in Figure 4, societal savings would increase by more than $\$ 4$ million for every $5 \%$ increase in case detection. This reflects the lower mortality that would result when more smear positive cases are detected and treated.

\section{Discussion}

We project that DOTS expansion in Haiti, to reach WHO targets, would cost an initial $\$ 4.2$ million and result in $28 \%$ reduction in $\mathrm{TB}$ cases, $49 \%$ reduction in mortality and net societal savings of $\$ 131$ million over 20 years. However, we project that the Haitian government would have to make significant initial investment and only begin to achieve savings after 15 years. Taken together, these

Table 5: Sensitivity analysis for projected savings over 20 years with DOTS expansion in Haiti

SAVINGS in \$US MILLIONS WITH DOTS EXPANSION *

PERSPECTIVE

\begin{tabular}{|c|c|c|c|c|}
\hline PARAMETER VARIED & CHANGE & NEW VALUE & SOCIETAL & GOVERNMENT \\
\hline Base Case (from Table 4) & Base & Base & $(\$|3|)$ & $(\$ 4)$ \\
\hline Initial DOTS investment & Double & $\$ 8.4$ million total & $(\$ 126)$ & $(\$ 0)$ \\
\hline Annual DOTS maintenance & Double & $\$ 722,000$ per year & $(\$ 128)$ & $(\$ I)$ \\
\hline $\begin{array}{l}\text { Annual DOTS maintenance }+ \text { cost of TB } \\
\text { drugs }\end{array}$ & Double both & $\$ 847,900$ per year & $(\$ 128)$ & $(\$ I)$ \\
\hline $\begin{array}{l}\text { Foreign Donor Pays: Initial + annual + TB } \\
\text { drugs }\end{array}$ & Eliminate all three & $\begin{array}{c}\$ 8.44 \text { million }+\$ 847,000 \\
\text { per year }\end{array}$ & $(\$ 138)$ & $(\$ 1 I)$ \\
\hline Change average duration of hospitalization & $\begin{array}{l}\text { Decrease with DOTS, } \\
\text { increase with Non-DOTS }\end{array}$ & $\begin{array}{c}3 \text { days - DOTS } 60 \text { days } \\
\text { non-DOTS }\end{array}$ & $(\$ 165)$ & $(\$ 29)$ \\
\hline $\begin{array}{l}\text { Single (SDR) and Multi (MDR) Drug } \\
\text { resistance }\end{array}$ & $\begin{array}{l}\text { Double prevalence of drug } \\
\text { resistance }\end{array}$ & SDR : $40 \%$ MDR : $0.6 \%$ & $(\$ 13 \mid)$ & $(\$ 4)$ \\
\hline $\begin{array}{l}\text { Impact of DOTS expansion on TB } \\
\text { incidence in subsequent years }\end{array}$ & $\begin{array}{l}\text { None } \\
1 / 3 \text { of base } \\
2 / 3 \text { of base }\end{array}$ & $\begin{array}{l}0 \% \text { annual decline } \\
2 \% \text { annual decline } \\
4 \% \text { annual decline }\end{array}$ & $\begin{array}{l}(\$ 6 I) \\
(\$ 88) \\
(\$ 1 \mid I)\end{array}$ & $\begin{array}{l}\$ 14 * \\
\$ 7 * \\
\$ 1 *\end{array}$ \\
\hline
\end{tabular}

Notes:

* A number in parentheses indicates net societal or government savings, while a number not in parentheses indicates a net increased cost with DOTS expansion,. 


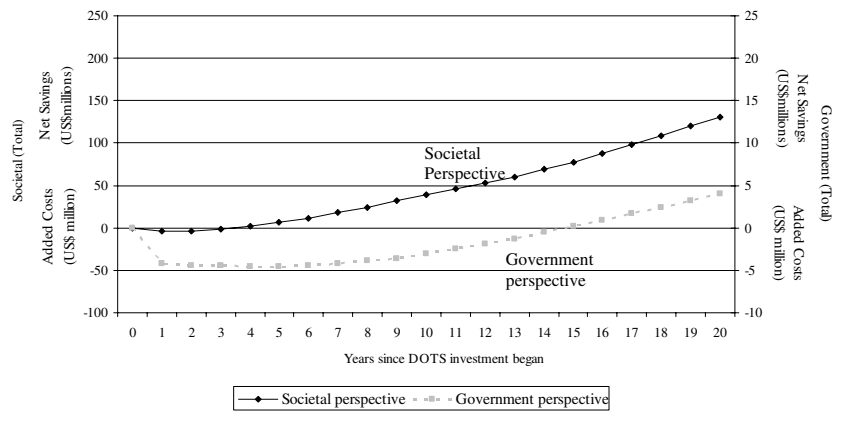

Figure 2

Year by year costs or savings with DOTS expansion in Haiti from societal and government perspectives. Dashed line government perspective, solid line - societal perspective.

findings should provide a powerful argument for foreign donors to support initial DOTS expansion in Haiti.

Several findings deserve comment. We have projected savings totalling \$26 million for patients and their families from DOTS expansion. Among the patients surveyed, direct out-of-pocket expenditures and lost income represented $49 \%$ and $27 \%$ respectively of the average yearly per capita income in Haiti. And patients surveyed also reported a substantial drop in income at the time of the survey compared to prior to onset of their illness. Savings are anticipated with DOTS expansion, because the decentralisation of diagnostic and treatment services should result in faster diagnosis [17-19], reduced hospitalisation $[15,16]$, and reduced out-of-pocket expenses for treatment and follow-up. Such projected benefits should make DOTS expansion a top priority for donors supporting the Millennium Development goal of poverty reduction [51].

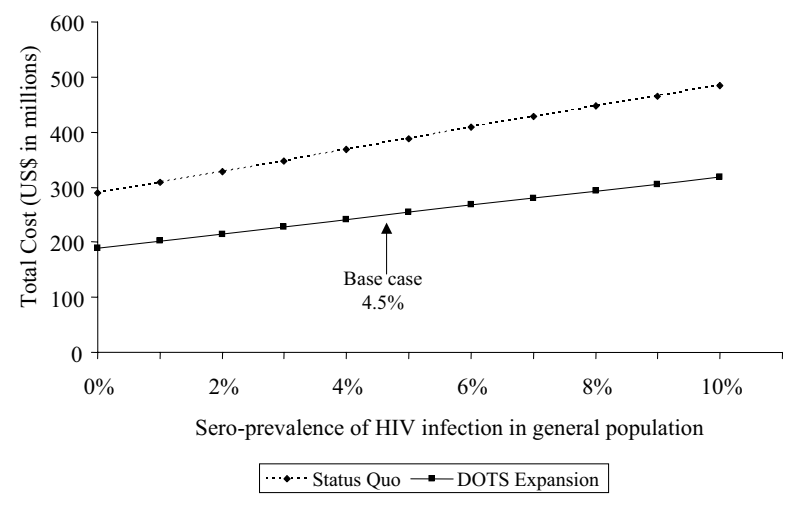

Figure 3

Effect of differences in HIV sero-prevalence on the projected cumulative total TB related costs over 20 years in Haiti with the two strategies. Dashed line - status quo, solid line - DOTS expansion.

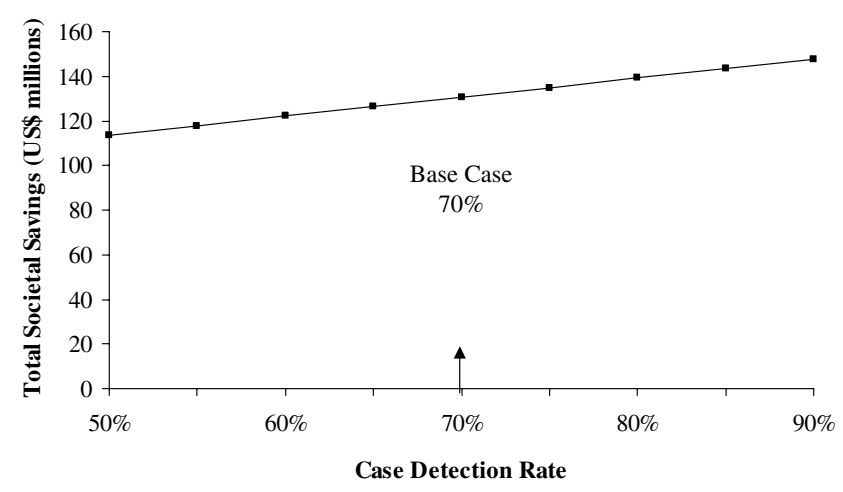

Figure 4

Effect of changes in the case detection rate with DOTS expansion on total societal savings over 20 years in Haiti.

The estimated current government expenditures of $\$ 432$ per TB patient were surprisingly high - very close to the average per capita income of $\$ 440$ [9]. We project potential savings from reduced hospitalization, but these will only be realized if hospital expenditures are actually reduced (i.e., by closing beds and reducing staffing). As well any such savings will be offset by increased expenditures for directly observed treatment, and staff supervision, quality control and training. These costly activities are essential for maintenance of a proper DOTS programme [52], but are not necessarily components of TB control programmes prior to DOTS expansion. Therefore new positions must be created, and new workers found with different knowledge and skills - a formidable challenge in many low-income countries. And, immediate government expenditures are required, while savings will only begin after 15 years. As Harold Wilson pointed out "a week is a long time in politics"; most governments will consider 15 years far too long to wait for a payback. Hence, there is little immediate incentive for the Haitian government to implement DOTS.

Another important component of projected government expenditures following DOTS expansion will be lab costs, totalling $\$ 9.6$ million, or $17 \%$ of all TB related government expenditures over 20 years. This reflects the high labour costs for smear microscopy [53], which can take up to 20 minutes of technician time per specimen [52]. In Peru only $2 \%$ of TB suspects investigated are smear positive [54], meaning that up to 150 negative smears are examined for each new case found. If treatment success exceeds $85 \%$, enhanced case detection is essential for the long-term epidemiologic impact of DOTS, given the high mortality, and contagiousness of undiagnosed cases. However, given our projections of substantial expenditures for smear microscopy, a high priority should be 
given to replacing this labour intensive cornerstone of the DOTS strategy.

This study is novel in that we conducted direct surveys to ascertain costs of health facilities, the national TB programme, and TB patients themselves. In this impoverished nation, patient and government expenditures for TB are remarkably high. We combined this direct data gathering with estimates of disability, costs for DOTS expansion, and TB drugs from published experience elsewhere. Additional strengths include the complex decision analysis model which incorporated five TB related health states (with one of three underlying $\mathrm{TB}$ drug resistance states) and three HIV related health states within the same model. As well published estimates of risk of TB and HIV infection, HIV progression, development and outcomes of active TB, and mortality were used.

However, there were a number of important potential limitations of this decision analysis. These included our assumptions regarding impact of DOTS on incidence, prevalence of HIV and drug resistance, stability of the population, methods of calculation of annual risk of infection, and costs for DOTS expansion. The assumption that incidence would decline $6 \%$ annually following DOTS expansion was based on observations in Peru after nationwide DOTS implementation [5]. This rate of decline is midway between two recent estimates - of $4.3 \%$ annually observed with DOTS in China [55], and 7.5\% annually predicted for countries achieving WHO targets [56]. And, in sensitivity analyses, societal savings were still substantial even with the extreme assumption of no change in incidence at all. We calculated annual risk of new TB infection from estimated incidence using the Styblo formula [14] - which has been criticized [57]. However, the same formula was applied to both strategies in all years, so inaccuracies in the estimate of infection rates would have been similar for both strategies. We may have over-estimated societal savings because we did not account for other illnesses causing health care costs or disability among those who survived with active TB. However these potential costs should be relatively low since the average age of the patients with active TB in Haiti was 34 so that even those with the most gains in survival would only be 54 by the end of 20 years. As well we did account for mortality from HIV infection (from published studies), and all other causes (from WHO life tables for the general population of Haiti). Thus the most important future societal costs among the added survivors with DOTS, were accounted for in the analysis.

Costs for DOTS expansion are difficult to estimate as there is little published experience to date. For this analysis, costs for expansion were based on published experience in Ecuador [48]. Given the social, economic, and epidemi- ologic differences between Ecuador and Haiti, these estimates may not be considered valid for Haiti. However these estimated costs were higher than actual costs incurred for a DOTS expansion project in India [58] where the economic situation is very similar to Haiti [9].

A very important limitation of our analysis is the assumption that basic government health services would continue to operate. Therefore we only accounted for the additional costs of DOTS expansion and maintenance. Continued basic government health services in Haiti, depends upon political stability, which is among the worst in the Americas. This problem has contributed to the current problems of the national TB control programme. But, the DOTS strategy has been successfully implemented and maintained amidst major civil conflicts in Mozambique and Nicaragua. Therefore we believe our findings should not be dismissed as overly optimistic by foreign donors considering investment in TB control in Haiti.

We assumed that HIV seroprevalence would remain constant over the next 20 years even though HIV seroprevalence has risen in most developing countries over the past two decades. However if HIV seroprevalence did increase, with a corresponding increased incidence of TB, societal saving would be greater with DOTS (Figure 3), because of improved case detection with corresponding reduction in mortality of undiagnosed active TB in HIV infected. We did not model the potential effect of large scale provision of antiretroviral therapy (ART). This is just being introduced in Haiti and other low income countries, so the costs, efficacy, and population impact of ART are currently unknown. Our assumption of unchanged drug resistance may be incorrect. However, in sensitivity analysis, even when the prevalence of drug resistance was doubled, results were very similar. We also assumed no population growth for Haiti, despite current annual growth of $1.4 \%$ [23]. However, a larger population would simply mean more new infections, and new active cases - with either strategy. And, as with higher HIV sero-prevalence, DOTS would be even more cost-saving relative to the status quo strategy.

We have projected that DOTS expansion in Haiti could prevent a large number of TB cases, and TB deaths, with substantial resultant societal savings. But this would require significant Haitian government investment which may be difficult to ensure, given current political instability and the prospect of little payback after many years. Given this, and the substantial potential humanitarian, economic, and public health benefits, we conclude that foreign donors should strongly consider investing in DOTS expansion in Haiti. 


\section{Competing interests}

The author(s) declare that they have no competing interests.

\section{Authors' contributions}

V. J. - Conception of project, data gathering, drafting manuscript

W. M. - Data gathering and critical revisions of manuscript

K. S. - Conception of project, data analysis, critical revisions of manuscript

O. O. - Conception of project, data gathering, data analysis, critical revisions of manuscript

G. B. - Conception of project, data analysis, critical revisions of manuscript

F. G. - Conception of project, and critical revision of manuscript

D. M. - Conception of project, data gathering, data analysis, drafting manuscript

\section{Acknowledgements}

We are grateful to many staff of the National TB Programme in Haiti, Sarah Hoibak for assistance in the health facility and patient costs questionnaire, Jason McKnight for assistance in data analysis, and Catherine Michaud for seemingly endless revisions of this manuscript.

Supported by a grant from the Rockefeller Foundation Drs. Schwartzman and Menzies are recipients of research career awards from the Fonds de Recherche en Santé du Québec. Dr. Barr is the recipient of a Robert Wood Johnson Generalist Physician Faculty Scholar Award.

\section{References}

I. Corbett EL, Watt CJ, Walker N, Maher D, Williams BG, Raviglione $\mathrm{MC}$, et al.: The growing burden of tuberculosis: global trends and interactions with the HIV epidemic. Arch Intern Med 2003, I63(9): 1009-1021.

2. Kochi A: The global tuberculosis situation and the new control strategy of the World Health Organization. Tuberc 1991, 72: $1-6$.

3. World Health Organization: Treatment of Tuberculosis: Guidelines for National Programmes. Geneva Second 1997.

4. Murray CJL, Styblo K, Rouillon A: Tuberculosis in developing countries: burden, intervention and cost. Bull Int Union Against Tuberculosis 1990, 65(I):2-20.

5. Suarez PG, Watt CJ, Alarcon E, Portocarrero J, Zavala D, Canales R, et al.: The dynamics of tuberculosis in response to 10 years of intensive control effort in Peru. J Infect Dis 200I, 184:473-478.

6. Floyd K, Blanc L, Raviglione M, Lee JW: Resources required for global tuberculosis control. Science 2002, 295(5562): 2040-204l.

7. Sachs ]: Macroeconomics and Health: Investigating in Health for Economic Development. World Health Organization 2001.

8. World Health Organization: Global Tuberculosis Control: Surveillance, Planning, Financing. In WHO Report Geneva, Switzerland; 2003.
9. The World Bank Group. Haiti Data Profile. I 2-8-2003 [http/ devdata.worldbank.org/external/CPPro file.asp? CCODE=HTI\&PTYPE=CP]

10. UNAIDS: Joint United Nations Programme on HIVIAIDS. 2002 [http://www.unaids.org/EN/default.asp\#].

II. Lee JW, Espinal M, Jaramillo E: Report of site visit to evaluate DOTS expansion in Latin America. World Health Organization, editor 2002.

12. Pitchenik AE, Russell BW, Cleary T, Pejovic I, Cole C, Snider D Jr: The prevalence of tuberculosis and drug resistance among Haitians. N Engl J Med 1982, 307(3): 162-165.

13. Scalcini M, Carré G, Jean-Baptiste M, Hershfield E, Parker S, Wolfe J, et al: Antituberculosis drug resistance in Central Haiti. Am Rev Respir Dis 1990, I42:508-5 I I.

14. Styblo K: The relationship between the risk of tuberculosis infection and the risk of developing infectious tuberculosis. Bull Int Union Tuberc 1985, 60(3-4): I I7-119.

15. Floyd K, Skeva J, Nyirenda T, Gausi F, Salaniponi F: Cost and costeffectiveness of increased community and primary care facility involvement in tuberculosis care in Lilongwe District, Malawi. Int J Tuberc Lung Dis 2003, 7(9 Suppl I):S29-S37.

16. Floyd K, Wilkinson D, Gilks C: Comparison of cost effectiveness of directly observed treatment (DOT) and conventionally delivered treatment for tuberculosis: experience from rural South Africa. BMJ 1997, 3 I 5(7 I 20): | 407-|4III.

17. Sherman LF, Fujiwara PI, Cook SV, Bazerman LB, Frieden TR: Patient and health care system delays in the diagnosis and treatment of tuberculosis. Int J Tuberc Lung Dis 1999, 3( I 2): 1088-1095.

18. Yamasaki-Nakagawa M, Ozasa K, Yamada N, Osuga K, Shimouchi A, Ishikawa N, et al.: Gender diference in delays to diagnosis and health care seeking behaviour in a rural area of Nepal. Int J Tuberc Lung Dis 200I, 5(I):24-3I.

19. Wandwalo ER, Mørkve O: Delay in tuberculosis case-finding and treatment in Mwanza, Tanzania. Int J Tuberc Lung Dis 2000, 4(2): $133-138$.

20. Caminero Luna JA: Guia de la Tuberculosis para Medicos Especialistas. In Union Internacional contra la Tuberculosis y Enfermedades Respiratorias (UICTER), editor. 6432 Imprime en France, Imprimerie Chirat; 2003. Depot Legal 2003 No 6432

21. Gupta R, Cegielski JP, Espinal MA, Henkens M, Kim JY, Lambregts-van Weezenbeek CSB, et al.: Increasing transparency in partnerships for health - introducing the Green Light Committee. Tropical Medicine and International Health 2002, 7(2):970-976.

22. Suarez PG, Floyd K, Portocarrero J, Alarcon E, Rapiti E, Ramos G, et al.: Feasibility and cost-effectiveness of standardised secondline drug treatment for chronic tuberculosis patients: a national cohort study in Peru. Lancet 2002, 359(9322): 1980-1989.

23. CIA - The World Factbook. CIA - The World Factbook. I 29-2003 [http://www.cia.gov/cia/publications/factbook/geos/ha.html]. Washington, DC, Central Intelligence Agency - USA

24. Sutherland I: The evolution of clinical tuberculosis in adolescents. Tuberc 1966, 47:308.

25. Van Zwanenberg D: The Influence of the number of bacilli on the development of tuberculous disease in children. Am Rev Respir Dis 1960, 82:31-44.

26. Ferebee $\mathrm{SH}$ : Controlled chemoprophylaxis trials in tuberculosis. Adv Tuberc Res 1969, 17:28-106.

27. Menzies D: Issues in the management of contacts of patients with active pulmonary tuberculosis. Can J Public Health 1997, 88 (3): 197-201.

28. Comstock GW, Edwards LB, Livesay VT: Tuberculosis morbidity in the US Navy: its distribution and decline. Am Rev Respir Dis 1974, I 1 0:572-580.

29. Nolan CM, Elarth AM: Tuberculosis in a cohort of Southeast Asian refugees: A five-year surveillance study. Am Rev Resp Dis 1988, 137:805-809.

30. Cummings KC, Mohle-Boetani J, Royce SE, Chin DP: Movement of tuberculosis patients and the failure to complete antituberculosis treatment. Am J Respir Crit Care Med I998, I57(4 Pt I): I249-I 252.

31. Chee CBE, Boudville IC, Chan SP, Zee YK, Wang YT: Patient and disease characteristics, and outcome of treatment defaulters from the Singapore TB control unit - a one-year retrospective survey. Int J Tuberc Lung Dis 2000, 4(6):496-503. 
32. Parthasarathy R, Prabhakar R, Somasundaram PR: A controlled clinical trial of 3- and 5-month regimens in the treatment of sputum-positive pulmonary tuberculosis in South India. Am Rev Respir Dis 1986, I34:27-33.

33. East African/British Medical Research Councils Study: Controlled clinical trial of five short-course (4-month) chemotherapy regimens in pulmonary tuberculosis: Second report of the 4th study. Am Rev Respir Dis 1981, I 23:165-170.

34. Singapore Tuberculosis Service/British Medical Research Council: Long-term Follow-up of a clinical trial of six-month and fourmonth regimens of chemotherapy in the treatment of pulmonary tuberculosis. Am Rev Respir Dis 1986, I 33:779-783.

35. Morgan D, Mahe C, Mayanja B, Okongo JM, Lubega R, Whitworth JA: HIV-I infection in rural Africa: is there a difference in median time to AIDS and survival compared with that in industrialized countries? AIDS 2002, I 6(4):597-603.

36. Wood R, Maartens G, Lombard C): Risk factors for developing tuberculosis in HIV-I - Infected adults from communities with low or very high incidence of tuberculosis. J Acquir Immune Defic Syndr 2000, 23:75-80.

37. Murray J, Sonnenberg P, Shearer SC, Godgrey-Faussett P: Human immunodeficiency virus and outcome of treatment for new and recurrent pulmonary tuberculosis in African patients. Am J Respir Crit Care Med 1999, I 59:733-740.

38. Chaisson RE, Clermont HC, Hole EA, Cantave M, Johnson MP, Atkinson J, et al:: Six-month supervised intermittent tuberculosis therapy in Haitian patients with and without HIV infection. Am J Respir Crit Care Med 1996, I 54:1034-1038.

39. Desvarieux M, Hyppolite PR, Johnson WD, Pape JW: A novel approach to directly observed therapy for tuberculosis in an HIV-endemic area. Am J Public Health 200I, 9 I (I): |38-|4 I.

40. Whalen C, Horsburgh CR, Hom D, Lahart C, Simberkoff M, Ellner J: Accelerated course of human immunodeficiency virus infection after tuberculosis. Am J Respir Crit Care Med 1995, I5I: I29-135.

4I. Connolly C, Reid, Davies G, Sturm W, McAdam K, Wilkinson D Relapse and mortality among HIV-infected and uninfected patients with tuberculosis successfully treated with twice weekly directly observed therapy in rural South Africa. AIDS 1999, I 3:1543-1547.

42. Beck-Sague C, Dooley SW, Hutton MD, Otten J, Breedan A, Crawford JT, et al:: Hospital outbreak of multi-drug resistant Mycobacterium tuberculosis infections: Factors in transmission to staff and HIV-infected patients. JAMA I992, 268: I 280-I 286.

43. Edlin BR, Tokars JI, Grieco MH, Crawford JT, Williams J, Sordillo EM, et al.: An outbreak of multi-drug resistant tuberculosis among hospitalized patients with the acquired immunodeficiency syndrome. New Engl J Med I992, 326(23): I5I4-I52I.

44. Lopez AD, Salomon J, Ahmad O, Murray CJL, Mafat D: Life Tables for 191 Countries: Data, Methods and Results. Geneva World Health Organization (GPE Discussion Paper Series: No.9); 2000.

45. Drummond MF, O'Brien B, Stoddart GL, Torrance GW: Methods for the economic evaluation of health care programmes. 2nd edition. New York: Oxford University Press; 1997

46. Weinstein MC, Siegel JE, Gold MR, Kamlet MS, Russell LB: Recommendations of the Panel on Cost-Effectiveness in Health and Medicine. JAMA 1996, 276(I 5): I253-1258.

47. Ainsworth M, Koda G, Lwihula G, Mujinja P, Over M, Semali I: Measuring the Impact of Fatal Adult Illness in Sub-Saharan Africa - An Annotated Household Questionnaire. In LSMS Living Standards Measurements Study Working Paper No.90 Washington, DC The World Bank; 1992.

48. Vaca J, Peralta H, Gresely L, Cordova R, Kuffo D, Romero E, et al: DOTS implementation in a middle income country - Development and evaluation of a novel approach. Int J Tuberc Lung Dis 2005, 9(5):52I-527.

49. World Bank Website 2004 [http://www.worldbank.org/data/ countrydata/countrydata.html]. Access date: April I5, 2004

50. Global Drug Facility: First-Line tuberculosis drugs\& formulations currently supplied/to be supplied by the global TB drug facility. World Health Organization, editor 2003 [http://stoptb.org/gdf/ drugsupply/drugs available.asp]. Access date: November 15, 2003

51. The World Bank Group: Achieving the MDG's and related outcomes: A framework for monitoring policies and actions. 2004 [http://www.developmentgoals.org/].
52. Management of Tuberculosis: A guide for low income countries. Fifth edition. International Union Against Tuberculosis and Lung Disease; 2000.

53. Roos BR, van Cleeff MRA, Githui WA, Kivihya-Ndugga L, Odhiambo JA, Kibuga DK, et al:: Cost-effectiveness of the polymerase chain reaction versus smear examination for the diagnosis of tuberculosis in Kenya: a theoretical model. Int J Tuber Lung Dis 1997, 2(3):235-24l.

54. Suarez P: Government of Peru MoH. In Tuberculosis en el Perú Informe 2000 Lima, Peru; 2001.

55. The effect of tuberculosis control in China. Lancet 2004, 364( 9432):417-422.

56. Elzinga G, Raviglione MC, Maher D: Scale up: meeting targets in global tuberculosis control. Lancet 2004, 363(94I I):8I4-8I9.

57. Borgdorff MW: Annual risk of tuberculous infection: time for an update? Bull World Health Organ 2002, 80(6):50I-502.

58. Khatri GA, Frieden TR: Controlling Tuberculosis in India. N Engl I Med 2002, 347( I 8): | 420- | 425

59. Burgess AL, Fitzgerald DW, Severe P, Joseph P, Noel E, Rastogi N, et al.: Integration of tuberculosis screening at an HIV voluntary counselling and testing centre in Haiti. AIDS 200I, I5: 1875-1879.

60. Dasgupta K, Schwartzman K, Marchand R, Tannenbaum TN, Brassard $P$, Menzies D: Comparison of cost effectiveness of tuberculosis screening of close contacts and foreign-born populations. Am J Respir Crit Care Med 2000, I 62(6):2079-2086

61. Comstock GM: How much isoniazid is needed for prevention of tuberculosis in immunocompetent adults. Int $J$ Tuberc Lung Dis 1999, 3( I 0):847-850.

62. Nolan CM, Aitken ML, Elarth AM, Anderson KM, Miller WT: Active tuberculosis after isoniazid chemoprophylaxis of Southeast Asian refugees. Am Rev Respir Dis 1986, I33:431-436.

63. Dye C, Espinal MA, Watt CJ, Mbiaga C, Williams BG: Worldwide incidence of multidrug-resistant tuberculosis. J Infect Dis 2002, I 85(8): I 197-1202.

64. Whalen CC, Johnson JL, Okwera A, Hom DL, Huebner R, Mugyenyi $P$, et al.: A trial of three regimens to prevent tuberculosis in Ugandan adults infected with the human immunodeficiency virus. In N Engl J Med Volume 337. Issue 12 Uganda-Case Western Reserve University Research Collaboration; 1997:801-808.

65. Guelar A, Gatell JM, Verdejo J, Podzamczer D, Lozano L, Aznar E, et al.: A prospective study of the risk of tuberculosis among HIV-infected patients. AIDS 1993, 7:1345-1349.

66. Grzybowski S, Barnett GD, Styblo K: Contacts of cases of active pulmonary tuberculosis. Bull IUAT 1975, 50:90-106.

67. Fischl MA, Uttamchandani RB, Daikos L, Poblete RB, Moreno JN, Reyes RR, et al: An outbreak of tuberculosis caused by multiple-drug resistant tubercle bacilli among patients with HIV infection. Ann Intern Med 1992, I I 7: I77-183.

68. Small P, Shafer R, Hopewell P: Exogenous reinfection with multidrug-resistant Mycobacterium tuberculosis in patients with advanced HIV infection. N Engl J Med I 993, 328: I I 37- I I 44

69. Daley CL, Small PM, Schecter GF, Schoolnik GK, McAdam RA, Jacobs WR, et al:: An outbreak of tuberculosis with accelerated progression among persons infected with the human immunodeficiency virus. New Engl J Med 1992, 326(4):231-235.

70. Stead WW: Management of health care workers after inadvertent exposure to tuberculosis: A guide for use of preventive therapy. Ann Intern Med 1995, I 22:906-912.

7I. Rieder HL: Epidemiologic basis of tuberculosis control. First edition. Paris, France, International Union Against Tuberculosis and Lung Disease; 1999:I-162.

72. Grzybowski S, Enarson DA: The fate of cases of pulmonary tuberculosis under various treatment programmes. Bull Int Union Tuberc 1978, 53(2):70-74.

73. Horwitz O: Public health aspects of relapsing tuberculosis. Am Rev Respir Dis 1969, 99:183-193.

74. Cohn DL, Catlin BJ, Peterson KL, Judson FN, Sbarbaro JA: A 62 dose, 6-month therapy for pulmonary and extrapulmonary tuberculosis. A twice-weekly, directly observed, and costeffective regimen. Ann Intern Med 1990, I I 2(6):407-4I 5.

75. Results at 5 years of a controlled comparison of a 6-month and a standard I8-month regimen of chemotherapy for pulmonary tuberculosis. Am Rev Respir Dis 1977, I I 6(I):3-8. 
76. Somner AR: Short-course chemotherapy in pulmonary tuberculosis. A controlled trial by the British Thoracic Association (third report). Lancet 1980, I(8 I 79): I I82-I I83.

77. Controlled clinical trial comparing a 6-month and a I2month regimen in the treatment of pulmonary tuberculosis in the Algerian Sahara. Algerian working group/British Medical Research Council cooperative study. Am Rev Respir Dis 1984, I 29(6):921-928.

78. Benator D, Bhattacharya M, Bozeman L, Burman W, Cantazaro A, Chaisson $R$, et al:: Rifapentine and isoniazid once a week versus rifampicin and isoniazid twice a week for treatment of drugsusceptible pulmonary tuberculosis in HIV-negative patients: a randomised clinical trial. Lancet 2002, 360(9332): 528-534.

79. Espinal MA, Kim SJ, Suarez PG, Kam KM, Khomenko AG, Migliori GB, et al:: Standard short-course chemotherapy for drug-resistant tuberculosis: treatment outcomes in 6 countries. JAMA 2000, 283(1 9):2537-2545.

80. Mitnick C, Bayona J, Palacios E, Shin S, Furin J, Alcantara F, et al.: Community-based therapy for multidrug-resistant tuberculosis in Lima, Peru. N Engl J Med 2003, 348(2): I I9- 128.

81. Deschamps MM, Fitzgerald DW, Pape JW, Johnson WD: HIV Infection in Haiti: Natural History and Disease Progression. AIDS 2000, I 4:2515-252I.

82. Malkin JE, Prazuck T, Simonnet F, Yameogo M, Rochereau A, Ayerour $J$, et al:: Tuberculosis and human immunodeficiency virus infection in West Burkina Faso: clinical presentation and clinical evolution. Int J Tuberc Lung Dis 1997, I(I):68-74.

83. Johnson JL, Okwera A, Vjecha MJ, Byekwaso F, Nakibali J, Nyole S, et al: Risk factors for relapse in human immunodeficiency virus type I infected adults with pulmonary tuberculosis. Int J Tuberc Lung Dis 1997, I(5):446-453.

84. Sonnenberg P, Murray J, Glynn JR, Shearer S, Kambashi B, GodfreyFaussett P: HIV-I and recurrence, relapse, and reinfection of tuberculosis after cure: a cohort study in South African mineworkers. Lancet 200I, 358(9294): I687-I693.

85. Pulido F, Peña JM, Rubio R, Moreno S, González J, Guijarro C, et al.: Relapse of tuberculosis after treatment in human immunodeficiency virus-infected patients. Arch Intern Med 1997, I57: 227-23I.

86. Deas J: Haiti's Response to Tuberculosis and Malaria. Application to the Global Fund to Fight AIDS TaM, editor 2002.

\section{Pre-publication history}

The pre-publication history for this paper can be accessed here:

http://www.biomedcentral.com/1471-2458/6/209/pre

pub
Publish with Biomed Central and every scientist can read your work free of charge

"BioMed Central will be the most significant development for disseminating the results of biomedical research in our lifetime. "

Sir Paul Nurse, Cancer Research UK

Your research papers will be:

- available free of charge to the entire biomedical community

- peer reviewed and published immediately upon acceptance

- cited in PubMed and archived on PubMed Central

- yours - you keep the copyright

Submit your manuscript here:

http://www.biomedcentral.com/info/publishing_adv.asp
BiolMedcentral 